\title{
MEDICAL IMAGING SYSTEMS TECHNOLOGY
}

Methods in General Anatomy 
MEDICAL IMAGING SYSTEMS TECHNOLOGY

A 5-Volume Set

Editor: Cornelius T Leondes (University of California, USA)

Analysis and Computational Methods

ISBN 981-256-993-6

Modalities

ISBN 981-256-992-8

Methods in General Anatomy

ISBN 981-256-991-X

Methods in Diagnosis Optimization

ISBN 981-256-990-1

Methods in Cardiovascular and Brain Systems

ISBN 981-256-989-8 


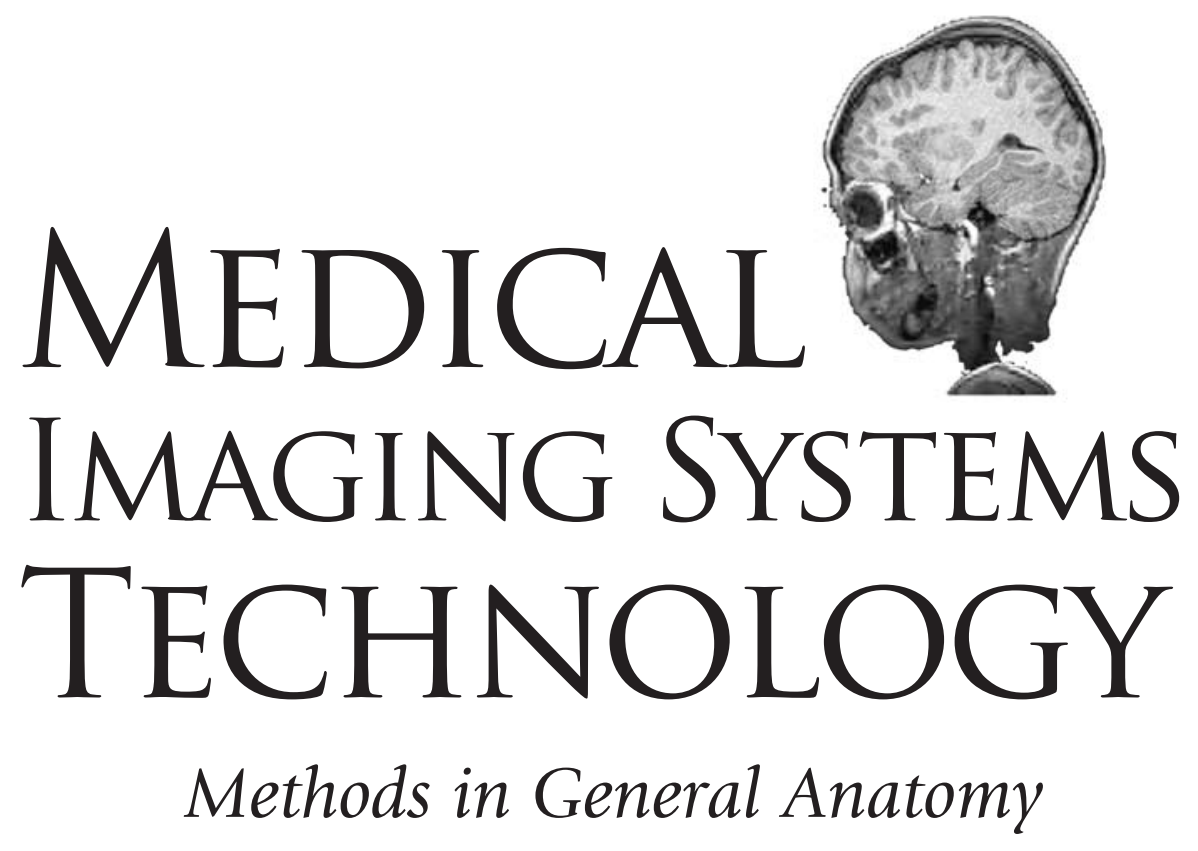

A 5-Volume Set
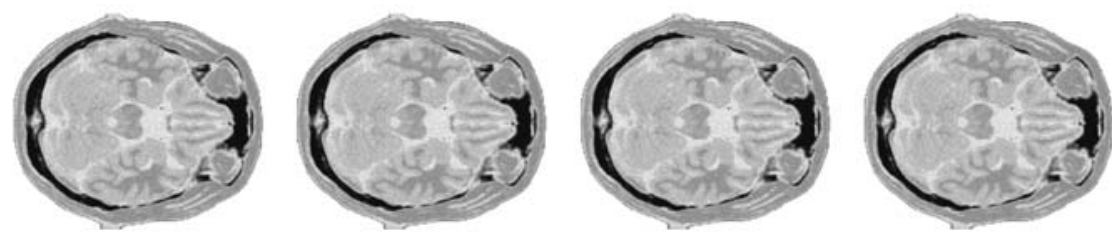

editor

Cornelius T Leondes University of California, Los Angeles, USA 


\section{Published by}

World Scientific Publishing Co. Pte. Ltd.

5 Toh Tuck Link, Singapore 596224

USA office: 27 Warren Street, Suite 401-402, Hackensack, NJ 07601

UK office: 57 Shelton Street, Covent Garden, London WC2H 9HE

\section{British Library Cataloguing-in-Publication Data}

A catalogue record for this book is available from the British Library.

\section{MEDICAL IMAGING SYSTEMS TECHNOLOGY \\ A 5-Volume Set \\ Methods in General Anatomy}

Copyright $(92005$ by World Scientific Publishing Co. Pte. Ltd.

All rights reserved. This book, or parts thereof, may not be reproduced in any form or by any means, electronic or mechanical, including photocopying, recording or any information storage and retrieval system now known or to be invented, without written permission from the Publisher.

For photocopying of material in this volume, please pay a copying fee through the Copyright Clearance Center, Inc., 222 Rosewood Drive, Danvers, MA 01923, USA. In this case permission to photocopy is not required from the publisher.

ISBN 981-256-364-4 (Set)

ISBN $981-256-991-\mathrm{X}$

Typeset by Stallion Press

Email: enquiries@stallionpress.com

Printed in Singapore. 


\section{Preface}

Because of the availability of powerful computational techniques, new modality techniques such as Computer-Aided Tomography (CAT), Magnetic Resonance Imaging (MRI) and others, and because of the new techniques of imaging processing (machine vision), the lives of many patients will be saved, and the quality of all our lives improved. This marriage of powerful computer technology and medical imaging has spawned a new and growing generation of young dynamic doctors who hold PhDs in physics and/or computer science, along with their MDs. In addition, technologists and computer scientists, with their superb skills, are also deeply involved in this area of major significance.

This volume covers the subject of medical imaging systems - methods in general anatomy, by leading contributors on the international scene. This is one of the 5 volumes on medical imaging systems technology, and together they collectively constitute an MRW (Major Reference Work). An MRW is a comprehensive treatment of a subject requiring multiple authors and a number of distinctly-titled and well-integrated volumes. Each volume treats a specific subject area of fundamental importance in medical imaging. The titles of the respective 5 volumes which compose this MRW are:

- Medical Imaging Systems - Analysis \& Computational Methods

- Medical Imaging Systems - Modalities

- Medical Imaging Systems - Methods in General Anatomy

- Medical Imaging Systems - Methods in Diagnosis Optimization

- Medical Imaging Systems - Methods in Cardiovascular \& Brain Systems

Each volume is self-contained and stands alone for those interested in a specific volume. However, collectively this 5 -volume set evidently constitutes the first multivolume comprehensive reference dedicated to the multi-discipline area of medical imaging.

There are over 130 coauthors of this notable work and they come from 25 countries. The chapters are clearly written, self-contained, readable and comprehensive with helpful guides including introduction, summary, extensive figures and examples with in-depth reference lists. Perhaps the most valuable feature of this work is the breadth and depth of the topics covered. 
This volume on "Medical Imaging Systems - Methods in General Anatomy" includes essential subjects like:

(a) Medical imaging analysis of the three dimensional (3D) architecture of trabecular bone: Techniques and their applications

(b) Medical image-based preformed titanium membranes for bone reconstruction

(c) Techniques for tracheal segmentation in medical imaging

(d) Knowledge-based system for contouring the spinal cord in computed tomography images

(e) From global to local approaches for non-rigid registration

(f) Automated image segmentation: Issues and applications

(g) Techniques in image guided surgery based on integrated rate sensing, segmentation and registration framework methods

(h) Image registration and fusion for interventional MRI-guided treatment of prostate cancer

(i) Detection and segmentation of Drusen deposits on retina images

The contributors of this volume clearly reveal the effectiveness of the techniques available and the essential role that they will play in the future. I hope that practitioners, research workers, computer scientists, and students will find this set of volumes to be a unique and significant reference source for years to come. 


\section{Contents}

Preface $\quad$ V

Chapter 1

Medical Imaging Analysis of the Three Dimensional (3D)

Architecture of Trabecular Bone: Techniques and their Applications

Agostino P. Accardo, Igor Strolka, Renato Toffanin and Franco Vittur

Chapter 2

Medical Image-Based Preformed Titanium Membranes for

Bone Reconstruction

V. Pattijn, F. Gelaude, J. Vander Sloten and R. Van Audekercke

Chapter 3

Techniques for Tracheal Segmentation in Medical Imaging

Raquel Valdés-Cristerna, Oscar Yáñez-Suárez and

Verónica Medina-Bañuelos

Chapter 4

Knowledge-Based System for Contouring the Spinal Cord in Computed Tomography Images

Neculai Archip, Pierre-Jean Erard and Robert Rohling

Chapter 5

From Global to Local Approaches for Non-Rigid Registration

Isabelle Corouge, Pierre Hellier and Christian Barillot

Chapter 6

Automated Image Segmentation: Issues and Applications

Alain Pitiot, Hervé Delingette and Paul M. Thompson

\section{Chapter 7}

Brain Shift Estimation for Image Guided Surgery Based on an Integrated Range-Sensing, Segmentation and

Registration Framework

Michel A. Audette, Kaleem Siddiqi, Frank P. Ferrie and Terry M. Peters 


\section{Chapter 8}

Image Registration and Fusion for Interventional MRI-Guided Treatment of Prostate Cancer

Baowei Fei and David L. Wilson

\section{Chapter 9}

Detection and Segmentation of Drusen Deposits on

\section{Retina Images}

Rapantzikos Konstantinos, Zervakis Michalis and Balas Konstantinos

Index 